\title{
Depressive symptoms, maternal feeding styles, and preschool child's body weight
}

\author{
Yolanda Flores-Peña, ${ }^{1}$ María Eugenia Pérez-Campa ${ }^{2}$ Hermelinda Ávila-Alpirez, ${ }^{3}$ \\ Juana Mercedes Gutiérrez-Valverde, 'Gustavo Gutiérrez-Sánchez ${ }^{3}$
}

Facultad de Enfermería, Universidad Autónoma de Nuevo León, México.

2 Hospital Metropolitano Dr. Bernardo Sepúlveda, San Nicolás de los Garza, Nuevo León, México.

${ }^{3}$ Unidad Académica Multidisciplinaria Matamoros, Universidad Autónoma de Tamaulipas, México.

Correspondence:

Yolanda Flores-Peña

Facultad de Enfermería, Universidad

Autónoma de Nuevo León.

Ave. Gonzalitos 1500 Nte.

Col. Mitras Centro,

64460 Monterrey, Nuevo León,

México.

Email: yolanda.florespe@uanl.edu.mx

Received: 7 October 2020

Accepted: 28 December 2020

Citation:

Flores-Peña, Y., Pérez-Campa, M. E. Ávila-Alpirez, H., Gutiérrez-Valverde, J. M., \& Gutiérrez-Sánchez, G (2021). Depressive symptoms, maternal feeding styles, and preschool child's body weight. Salud Mental, $44(6), 261-266$

DOI: $10.17711 /$ SM.0185-3325.2021.034

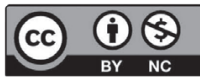

\begin{abstract}
Introduction. Depressive symptoms (DS) can impact maternal child feeding styles (MCFS), and child's body weight. Objective. 1. Verify if DS are different depending if the child has, or not, overweight-obesity (OW-OB); 2. Identify the MCFS based on the fact that the child has, or not, OW-OB; 3. Verify it DS are different according to MCFS; 4. Identify DS's predictors. Method. Correlational cross-sectional study. The participants were 259 dyads (mother- preschool child) residents in Mexico' Northeast. Mothers answered the Center for Epidemiologic Studies Depression Scale, Revised, and the Caregiver Feeding Styles Questionnaire. Mann-Whitney U test, Chi-square test, Kruskall-Wallis $\mathrm{H}$, and multiple linear regression analysis were performed. Results. Twelve point eight percent of the mothers $(n=33)$ had DS, 35.5\% $(n=92)$ authoritarian MCFS. No significant difference was identified between DS and MCFS according to the child's OW-OB or lack thereof $(U=5726.0, p>.05$ and $\left.\mathrm{X}^{2}=.078, g l=3, p>.05\right)$. A significant positive correlation was found between DS and MCFS demandingness $\left(r_{\mathrm{s}}=.208, p=.001\right)$. The authoritarian MCFS had the highest DS mean $(H=10.70, g l=3, p<.05)$. The demandingness predicts the DS $\left(X^{2}=826.445, g l=1, p=.001\right)$. Discussion and conclusion. Authoritarian MCFS predominated, DS were higher in mothers with authoritarian MCFS; demandingness predicts DS. It is recommended to promote authoritarian MCFS which favors the development of healthy eating habits.
\end{abstract}

Keywords: Depression, body weight, preschool, feeding, mother-child relationships, overweight.

\section{RESUMEN}

Introducción. Los síntomas depresivos (SD) pueden afectar en los estilos maternos de alimentación infantil (EMAI) y peso corporal del hijo. Objetivo. 1. Verificar si los SD son diferentes de acuerdo con sí/no sobrepeso-obesidad (SP-OB) del hijo; 2. Identificar el EMAI de acuerdo con si/no SP-OB del hijo; 3. Verificar si los SD son diferentes de acuerdo con el EMAl; 4. Identificar predictores de los SD. Método. Estudio transversal correlacional. Participaron 259 diadas (madre-hijo preescolar) residentes en el Noreste de México. Las madres contestaron la Escala Revisada de Depresión del Centro de Estudios Epidemiológicos y el Cuestionario Estilos de Alimentación del Cuidador. Para el análisis se usaron U de Mann-Whitney, Chi-cuadrada, Kruskall-Wallis y regresión lineal múltiple. Resultados. 12.8\% $(n=33)$ de madres presentó SD, 35.5\% $(n=92)$ EMAI autoritario. No se identificó diferencia significativa entre los SD y el EMAI de acuerdo con sí-no SP-OB del hijo $(U=5726.0$, $p>.05$ y $\left.X^{2}=.078, g l=3, p>.05\right)$. Se encontró correlación positiva significativa entre SD y exigencia del EMAl $\left(r_{\mathrm{s}}=.208, p=.001\right)$. El EMAl autoritario tuvo la media más alta de SD $(H=10.70, g l=3, p<.05)$. La exigencia predice los SD $\left(X^{2}=826.445, g l=1, p=.001\right)$. Discusión y conclusión. Predominó el EMAl autoritario, los $\mathrm{SD}$ fueron mayores en las madres con EMAI autoritario, la exigencia predice los SD. Se recomienda promover el EMAI con autoridad, ya que favorece el desarrollo de hábitos saludables de alimentación.

Palabras clave: Depresión, peso corporal, preescolar, alimentación, relaciones madre-hijo, sobrepeso. 


\section{INTRODUCTION}

Childhood obesity is one of the most serious public health problems of the 21 st century. The prevalence has increased at an alarming rate. It is estimated that in 2016 more than 41 million children under five years, worldwide, were overweight (OW)-obese (OB) (World Health Organization, 2020a). Excess weight during childhood has effects on health, such as: hyperlipidemia, hypertension, and abnormal glucose tolerance (Gurnani, Birken, \& Hamilton, 2015). It has also been documented that a child with OW at the age of five is four times more likely to present $\mathrm{OB}$ at nine years of age compared to a normal-weight child at the same age (Cunningham, Kramer, \& Narayan, 2014).

Multiple factors interact in its etiology, including genetic predisposition, increased energy consumption, and decreased physical activity (Kumar \& Kelly, 2017). During childhood, family life is the main context that influencing the development of healty habits, and according to the traditional gender, role the mother is the main caregiver (Martinez, Rhee, Blanco, \& Boutelle, 2017), so she is in a unique position to influence the behaviors of the lifestyle of the child.

However, de Castro, Place, Villalobos, and Allen-Leigh (2015) reported the prevalence of depressive symptoms (DS) in Mexican mothers of children under five years of age was $19.91 \%$, which means that more than 4.6 million girls and boys live with mothers who might be suffering moderate or severe depression. Harris and Santos (2020) found evidence of a moderating and mediating role of maternal depression between contextual stressors and child outcome.

Depression is a common mental disorder characterized by the presence of sadness, loss of interest or pleasure, feelings of guilt, lack of self-esteem, sleep or appetite disorders, feelings of tiredness, and lack of concentration. All these can become chronic or persistent and significantly hinder performance at work or school and the ability to cope with daily life (World Health Organization, 2020b).

It has been identified in Mexican population that DS are more prevalent among women who did not complete primary schooling, who are unemployed, who are not married or living in union with a partner, and with more than four children (de Castro et al., 2015). When a mother suffers from depression, important relationships could be affected, such as a mother-child relationship (Harris \& Santos, 2020).

On the other hand, Benton, Skouteris, and Hayden (2015) made a systematic review to identify relationships between maternal psychopathology variables including DS, and risks for preschooler obesity, and found positive associations between DS, and increased risks for preschooler obesity in the majority of studies. Another research in which low-income mothers participated, found that $31 \%$ of the participants presented DS above the CESD-R threshold (score $\geq 16$ ) (The Center for Epidemiologic Studies Depression Scale Revised, CESD, 2020) and documented that mothers with high DS reported greater pressure to eat, restriction, and demandingness in feeding. In addition, children were less likely to eat at the kitchen/dining room table, the television had a higher volume during meals, and mothers were less likely to eat with their children (Goulding et al., 2014).

Another two-year follow-up study found that children of mothers with episodic or severe chronic DS were more likely to have OW-OB compared to the children of mothers with moderate episodic DS or few symptoms, and it was also found that these mothers had lower scores in the feeding style responsiveness dimension (Marshall et al., 2018). Regarding the concept of child feeding styles, it refers to the attitude and emotional climate that parents use in the interaction with their child at feeding time. It involves two dimensions, demandingness and responsiveness, which when combined, incorporate four styles: authoritative feeding style (high demandingness / high responsiveness), authoritarian feeding style (high demandingness / low responsiveness), indulgent feeding style (low demandingness / high responsiveness), uninvolved feeding style (low demandingness / low responsiveness). In the light of this childhood OB has been found to be more prevalent in children with parents with an authoritarian and indulgent feeding style (El-Behadli, Sharp, Hughes, Obasi, \& Nicklas, 2015).

As mentioned before, given that childhood OB is an important public health problem, it is relevant to study the factors associated with excess weight during this stage of development. Furthermore, no studies were found that addressed DS, MCFS, and child' BMI in Mexican population. The objectives of the study were:

1. To verify if DS are different depending if a child has, or not, overweight-obesity (OW-OB).

2. To identify the Maternal Child Feeding Style (MCFS) based on the fact that the child has, or not, overweight-obesity (OW-OB).

3. To verify it DS are different according to MCFS.

4. To identify DS' predictors: maternal variables (age, marital status, schooling, number of children, demandingness, and responsiveness) and those of the child (sex and BMI).

\section{METHOD}

\section{Design of the study}

Correlational cross-sectional study.

\section{Subjects}

\section{Description of the sample}

Dyads (mother-child preschool) participated. To calculate the sample, students enrolled $(n=961)$ in 10 randomly selected preschool institutions in the state of Nuevo León, Mexico, 
were considered. The sample was calculated for a multiple linear regression confidence interval of .95 and test power of $95 \%$, which resulted in a sample size of 259 . A $10 \%$ of attrition or missing information was also considered. For this reason, 284 mothers were invited to participate. The participants were selected by stratified sampling according to the size of the stratum (each one of the institutions was the stratum), afterwards the mothers were selected randomly from the educational institutions of their enrolled child. The questionnaires in which the mothers reported that the child suffered from some disease that affected growth, such as endocrine disease and asthma $(n=6)$, as well as incomplete questionnaires $(n=8)$ or those with duplicate answers $(n=8)$, and missing information were eliminated $(n=3)$. The period of recruitment was August to December 2015.

\section{Inclusion criteria}

Mothers who admitted having a child enrolled in one of the selected institutions were included in the study.

\section{Exclusion criteria}

Mothers were excluded from the study if they reported that their child had a motor limitation or required special feeding. Having a child who had previously received a medical diagnosis for a disease that would limit their growth and development (e.g., type I diabetes mellitus was also a exclusion criterion).

\section{Measurements}

The chosen mothers answered the Center for Epidemiologic Studies Depression Scale Revised (CESD-R) created in 1977 by Laurie Radloff and revised in 2004 by William Eaton and collaborators. (CESD, 2020). The CESD-R is a screening instrument for the detection of depression cases based on symptoms during the last two weeks. It has good psychometric properties, high internal consistency, and thus it is considered a valid measure for depression in the general population (it is available on the internet) (Van Dam \& Earleywine, 2011).

The CESD-R consists of 20 items, integrated into nine sub-scales: 1. Sadness (Dysphoria), 2. Loss of interest (Anhedonia), 3. Appetite, 4. Sleep, 5. Thinking/concentration, 6. Guilt (Worthlessness), 7. Tired (Fatigue), 8. Movement (Agitation), and 9. Suicidal ideation, with response options ranging from: $0=$ Not a all or less than one day, $1=1-2$ days, $3=$ 5-7 days, and $4=$ nearly every day for 2 weeks.

After adding up the responses and according to the cutoff point $\geq 16<$ and determining whether they suffered from dysphoria or anhedonia, the answers are classified into the following categories: 1. major depressive episode: anhedonia and dysphoria nearly every day for the past two weeks, plus symptoms in an additional four symptom groups; 2 . probable major depressive episode: anhedonia or dysphoria, in an additional three symptom groups; 3. possible major depressive episode: anhedonia or dysphoria, plus two other symptom groups; 4. subthreshold depression symptoms: score greater than 16 without anhedonia or dysphoria; and 5. no clinical significance: score less than 16 .

To evaluate the MCFS, the Caregiver Feeding Styles Questionnaire (CFSQ) was applied, which consists of 19 items that evaluate eating styles with a Likert-type response scale ranging from 1 . never to 5 . always. The items are grouped into two dimensions, demandingness, and responsiveness; the first is the average of the sum of the 19 items and responsiveness the latter is the totality of the seven items focused on the child $(3,4,6,8,9,15$, and 17) divided by the average of the sum of the 19 items.

Subsequently, the median of both dimensions is calculated, which are the cut-off point to define whether the dimension is high or low and categorize the participant in one of the four feeding styles: 1. authoritative (high demandingness / high responsiveness), 2. authoritarian (high demandingness / low responsiveness), 3. indulgent (low demandingness / high responsiveness), and 4. uninvolved (low demandingness / low responsiveness). The CFSQ has reported a test-retest correlation $(r=.79)(p<.001)$ for demandingness and $(r=.75)(p<.001)$ for responsiveness (Hughes, Power, Orlet Fisher, Mueller, \& Nicklas, 2005).

The preschool child's weight was measured with a Seca 813 scale with a capacity for 200 kilograms .1 gram precision and their height was measured with the Seca 214 stadiometer which was recorded at the closest point to $.1 \mathrm{~cm}$, data were entry in WHO AnthroPlus (World Health Organization, 2009), child's BMI was calculated, and classified according to the BMI percentiles as: malnutrition $(<3$ percentile), underweight $(\geq 3$ and $<15$ ), normal weight $(\geq 15$ and $<85$ ), overweight $(\geq 85$ but $<97)$, and obese $(\geq 97)$. The measurements were performed by trained standardized personnel.

\section{Statistical analysis}

The data were entered and analyzed with the Statistical Package for the Social Sciences (SPSS), version 23; the distribution of the data was verified, and non-parametric statistics were applied. To verify if DS were different according to whether the child presented OW-OB, the Mann-Whitney $\mathrm{U}$ test was applied; and to identify the MCFS according to whether the child presented OW-OB, a contingency table was considered and the Chi-square test was applied. Spearman's Rho correlation and the Kruskall-Wallis H test were performed to explore the relationship between DS and MCFS, and a multiple linear regression analysis was performed to identify predictors of DS.

\section{Ethical Considerations}

The participating mothers gave their informed consent and their authorization to carry out anthropometric mea- 
surements of the child. The recommendations of the Declaration of Helsinki were followed. The Project was reviewed, approved, and registered by the Ethical Research Committee of the School of Nursing of the Autonomous University of Nuevo León (Universidad Autónoma de Nuevo León, UANL) (FAEN-M-1175).

\section{RESULTS}

First, the internal consistency of the questionnaires was evaluated using Cronbach's alpha coefficient. The Center for Epidemiologic Studies Depression Scale, Revised (CESD-R), obtained a Cronbach's alpha of .89; and both this the Caregiver Feeding Styles Questionnaire (CFSQ) .90 were considered acceptable.

There were 259 dyads (mother-child preschool). The mean maternal age was 30.02 years $(S D=6.68)$ with a schooling of 10.35 years $(S D=3.15)$. Most mothers lived with a partner $84.2 \%(n=218)$, the majority, $78.8 \%$ $(n=204)$, were housewives, $16.2 \%(n=42)$ carried out a non-professional job and $5 \%(n=13)$ had a professional job; the daily working hours average was seven hours $(S D=17 \mathrm{hrs})$; the information is shown in Table 1 .

Regarding DS, the scores were classified as whether $(>16)$ or not $(<16)$ there was presence of DS according to CESD (2020), and it was found that $87.2 \%(n=226)$ of the participants did not present DS and $12.8 \%(n=33)$

Table 1

Maternal variables

\begin{tabular}{lrc}
\hline Variables & $f$ & $\%$ \\
\hline Marital Status & 218 & 84.2 \\
$\quad$ With couple & 41 & 15.8 \\
$\quad$ Without couple & & \\
Occupation & 204 & 78.8 \\
$\quad$ Housewife & 42 & 16.2 \\
Non- professional job & 13 & 5.0 \\
Professional job & & \\
Depressive disorder category & 1 & .4 \\
$\quad$ Major depressive episode & 1 & .4 \\
Possible major depressive episode & 31 & 12.0 \\
Subthresholod depression symptoms & 226 & 87.2 \\
No clinical significance & & \\
Maternal feeding style & 45 & 17.4 \\
Authoritative & 40 & 15.4 \\
Uninvolved & 92 & 35.5 \\
Authoritarian & 82 & 31.7 \\
Indulgent & & \\
\hline
\end{tabular}

Notes: $f=$ frequency; $\%=$ percentage $; n=259$.
Table 2

Mann-Whitney $U$ test for depressive symptoms scores according to whether / not the child presents OW-OB

\begin{tabular}{lrccccc}
\hline Depressive symptoms & $n$ & $\overline{\mathrm{x}}$ & $\mathrm{Mdn}$ & $S D$ & $U$ & $p$ \\
\hline Condition & & & & & & \\
Yes OW-OB & 58 & 8.1 & 6.0 & 8.4 & 5726.0 & .837 \\
No OW-OB & 201 & 8.6 & 6.0 & 9.3 & & \\
Total & 259 & 8.5 & 6.0 & 9.1 & & \\
\hline
\end{tabular}

Notes: $\overline{\mathrm{x}}=$ mean; $\mathrm{Mdn}=$ Median; $S D=$ Standard Deviation; $n=259 ; \mathrm{U}=$ Mann-Whitney $U$ statistic; $p=p$ value.

did so. When classifying the scores into categories, it was found that $12 \%(n=31)$ fell into the subthreshold depression category.

The median of demandingness (2.57) and responsiveness (1.16) were obtained in order to describe the MCFS, and according to this, high or low were identified and the participants were classified in one of the four MCFS. An authoritarian style was found in 35.5\% $(n=92)$, followed by indulgent style $31.7 \%(n=82)$ (Table 1$)$. Regarding children, $52.1 \%(n=135)$ were male and $47.5 \%(n=123)$ female, average age of 4.39 years old $(S D=.69), 22.4 \%(n=58)$ presented OW-OB and $62.2 \%(n=161)$ normal weight.

To respond the specific objective 1 that indicates to verify if the DS are different according to whether or not the child presented OW-OB, the Mann-Whitney U test was applied. No significant differences were found $(U=5726.0$, $p>.05)$ (Table 2).

Table 3 deals with objective 2 , that is to identify the MCFS according to whether or not the child presented OWOB. The Chi-square test was applied and it was found that regardless of the presence of OW-OB in the child, the authoritarian MCFS predominated $\left(\mathrm{X}^{2}=.780, g l=3, p>.05\right)$.

To verify it DS are different according to MCFS, the Kruskal-Wallis $\mathrm{H}$ test was applied and it was observed that the authoritarian style obtained the highest DS score $(H=10.70, g l=3, p<.05)$ (Table 4).

Finally, to identify predictors of DS, the following were considered as independent variables: maternal (age, marital

Table 3

Maternal child feeding style according to whether / not the child presents $O W-O B$

\begin{tabular}{lccccc}
\hline Maternal child & \multicolumn{2}{c}{ No OW-OB } & & \multicolumn{2}{c}{ Yes OW-OB } \\
\cline { 2 - 3 } \cline { 5 - 6 } feeding style & $f$ & $\%$ & & $f$ & $\%$ \\
\hline Authoritative & 36 & 17.9 & & 9 & 15.5 \\
Authoritarian & 72 & 35.8 & & 20 & 34.5 \\
Indulgent & 64 & 31.8 & & 18 & 31.0 \\
Uninvolved & 29 & 14.3 & & 11 & 19.0 \\
Total & 201 & 100 & & 58 & 100 \\
\hline
\end{tabular}

Notes: $f=$ frequency; $\%=$ percentage; OW-OB $=$ overweight - obesity $; n=259$. 
Table 4

Depressive symptoms according to the maternal child feeding style

\begin{tabular}{lcccc}
\hline & \multicolumn{4}{c}{ Depressive symptoms } \\
\cline { 2 - 5 } MCFS & $f$ & $\overline{\mathrm{x}}$ & Mdn & $S D$ \\
\hline Authoritative & 45 & 9.33 & 7.00 & 9.38 \\
Authoritarian & 92 & 10.36 & 7.50 & 7.45 \\
Indulgent & 82 & 6.99 & 6.00 & 7.49 \\
Uninvolved & 40 & 6.55 & 4.50 & 7.45 \\
\hline
\end{tabular}

Notes: MCFS = Maternal child feeding style; $\bar{x}=$ mean; Mdn $=$ Median; $n=$ 259; $S D=$ Standard deviation

status, schooling, number of children, demandingness, and responsiveness) and of the child (sex and BMI) and multiple linear regression analysis was applied. The model was significant $\left(\chi^{2}=826.445, g l=1, p=.001\right)$. Using the Enter procedure with manual elimination of variables (first, variables not contribuing to the model were excluded), it was identified that the variable that contributed to the model was demandingness. Specifically, it is shown that for each unit that increased the demandingness, the probability of presenting DS also increased (Table 5).

\section{DISCUSSION AND CONCLUSION}

To identify the presence of DS, the CESD-R Scale was applied, having an acceptable internal consistency. It result should be noted that it is available in 11 languages with good psychometric properties, high internal consistency, and convergent validity; it is considered that the CESD-R is an overall accurate and valid depression measure in general and it is available online (Van Dam \& Earleywine, 2011). On the other hand, the Caregiver Eating Styles Questionnaire showed acceptable internal consistency; this questionnaire has been applied to Hispanic mothers living in the United States and to Mexican mothers as well (Flores-Peña et al., 2017; Hughes et al., 2005) and has shown acceptable internal consistency.

Regarding the presence of DS, most participants did not present symptoms; however, the presence of subthresh-

Table 5

Inferential statistics of the effect of the variables on the maternal child feeding style

\begin{tabular}{lccccc}
\hline Model & $\chi^{2}$ & $g l$ & $p$ & $R^{2}$ & \\
\hline Multiple linear regression & 826.445 & 1 & .001 & .039 & \\
\hline Variable & $B$ & $E E$ & $t$ & $\operatorname{Exp}(ß)$ & $P$ \\
\hline Model & & $\chi^{2}$ & $g l$ & $p$ & $R^{2}$ \\
\hline Constant & 1.77 & 2.16 & .824 & & \\
Requirement & 2.59 & .806 & 3.21 & .197 & .001 \\
\hline
\end{tabular}

Notes: $\chi^{2}=$ chi-square; $\mathrm{gl}=$ degrees of freedom; $p=$ significance value; $n=$ 259. old depression was identified, that is, the simultaneous presence of two or more symptoms of depression for most of the time during the last two weeks, less than what was reported in Mexican mothers (de Castro et al., 2015), and less than what was reported in another study in which low-income mothers living in the United States participated (Goulding et al., 2014). It is important to highlight that the participant mothers were selected based on having a child enrolled in public educational institutions in Monterrey, Nuevo León, a situation that could have constituted a bias at the time of answering the questionnaires.

The predominant MCFS was the authoritarian one, characterized by high demandingness and low responsiveness; in this regard, it has been described that the Mexican culture emphasizes respect for authority and the use of strict rules to discipline children. Also, it has been documented that the authoritarian style predicts a higher body weight on children (Melis Yavuz \& Selcuk, 2018), as well as the consumption of foods rich in fat and / or sugar (Vollmer, 2019). In addition to the authoritarian MCFS, an indulgent MCFS was found, which is characterized by low demand / high responsibility, which has also been identified in Latin mothers of Mexican origin living in the United States and related to higher scores for the child's BMI (Hidalgo-Mendez, Power, Fisher, O'Connor, \& Hughes, 2019). Also, the prevalence of childhood overweight and obesity identified in this study was higher than the prevalence reported in the Mexican National Health and Nutrition Survey, 2018 (Shamah-Levy et al., 2020).

On the other hand, it was not identified if maternal DS were different according to whether or not a child OWOB. Some authors point out this relationship when the DS are severe, a situation that was only identified in one participant. Likewise, it was found that the predominant MCFS was the authoritarian one, regardless of whether or not the child' OW-OB. It is important to notice that it has been documented that the predominant MCFS in Latin mothers living in the United States and Mexican mothers are authoritarian and indulgent (Hidalgo-Mendez et al., 2019; Olvera \& Power, 2010). Furthermore, the literature has pointed out a relationship between DS with children's OW-OB (El-Behadli et al., 2015), a relationship that is not confirmed in the present study. In this regard it is possible to point out that some authors note this relationship only when mothers present severe DS.

It was also identified that the highest average value of DS was found in the authoritarian MCFS and it was found that the dimension of demandingness is a determining factor of the DS. This finding is considered important given that, as indicated above, the literature documents that the MCFS that predominates among Hispanic mothers is the indulgent (Hidalgo-Mendez et al., 2019) while in Mexican mothers the authoritarian style predominates (Flores-Peña et al., 2017), which is characterized by controlling, managing limits and 
strict rules, which could lead mothers to a high level of stress and anxiety, seeing that their demands are not met, and therefore, they are more likely to cause depressive disorders.

\section{Limitations and recommendations}

An important limitation of the study was the low proportion of mothers that presented DS; the explained variance of the regression model was also very low. Other factors, such as child's sex, number of children, insecurity at home, and violence were not considered in the regression analysis (de Castro et al., 2015). Moreover, the study was cross-sectional, and included whether a child had overweight-obesity. According to this, longitudinal studies are recommended, as well as case-control studies, include clinical samples, mothers with depression medical diagnosis, and design of interventions aimed at promoting MCFS with authority (high demandingness / high responsiveness), and structure feeding practices (Vaughn et al., 2016).

\section{Conclusions}

- Most of the mothers did not present DS.

- The prevalence of DS was lower than the prevalence in Mexican mothers of children under five years identified in other study conducted in Mexican mothers.

- The most frequent MCFS is authoritarian, which presented the highest mean of DS.

- The prevalence of childhood overweight and obesity identified in this study was higher than the prevalence reported in the Mexican National Health and Nutrition Survey, 2018.

- The demandingness dimension predicts DS with very low explain variance.

- This results can only be extrapolated to participants with similar characteristics.

\section{Funding}

None.

\section{Conflict of interest}

The authors declare they have no conflicts of interest.

\section{Acknowledgements}

Secretaría de Educación Pública de Nuevo León and participant mothers.

\section{REFERENCES}

Benton, P. M., Skouteris, H., \& Hayden, M. (2015). Does maternal psychopathology increase the risk of pre-schooler obesity? A systematic review. Appetite, 87, 259-282. doi: 10.1016/j.appet.2014.12.227

Cunningham, S. A., Kramer, M. R., \& Narayan, K. M. (2014). Incidence of childhood obesity in the United States. The New England Journal of Medicine, 370(5), 403-411. doi: 10.1056/NEJMoa1309753

de Castro, F., Place, J. M., Villalobos, A., \& Allen-Leigh, B. (2015). Sintomatología depresiva materna en México: prevalencia nacional, atención y perfiles poblacionales de riesgo. Salud Pública de México, 57(2), 144-154.
El-Behadli, A. F., Sharp, C., Hughes, S. O., Obasi, E. M., \& Nicklas, T. A. (2015). Maternal depression, stress and feeding styles: towards a framework for theory and research in child obesity. The British Journal of Nutrition, 113(S1), S55-S71. doi: 10.1017/S000711451400333X

Flores-Peña, Y., Acuña-Blanco, A., Cárdenas-Villarreal, V. M., Amaro-Hinojosa, M. D., Pérez-Campa, M. E., \& Elenes-Rodríguez, J. R. (2017). Asociación de la percepción materna del peso del hijo y estilos maternos de alimentación infantil. Nutrición Hospitalaria, 34(1), 51-58. doi: 10.20960/nh.975

Goulding, A. N., Rosenblum, K. L., Miller, A. L., Peterson, K. E., Chen, Y. P., Kaciroti, N., \& Lumeng, J. C. (2014). Associations between maternal depressive symptoms and child feeding practices in a cross-sectional study of low-income mothers and their young children. The International Journal of Behavioral Nutrition and Physical Activity, 11, 75. doi: 10.1186/1479-5868-11-75

Gurnani, M., Birken, C., \& Hamilton, J. (2015). Childhood Obesity: Causes, Consequences, and Management. Pediatric Clinics of North America, 62(4), 821-840. doi: 10.1016/j.pcl.2015.04.001

Harris, R. A., \& Santos, H. P. Jr. (2020). Maternal depression in Latinas and child socioemotional development: A systematic review. PloS One, 15(3), e0230256. doi: 10.1371/journal.pone.0230256

Hidalgo-Mendez, J., Power, T. G., Fisher, J. O., O’Connor, T. M., \& Hughes, S. O. (2019). Child weight status and accuracy of perceived child weight status as predictors of Latina mothers' feeding practices and styles. Appetite, 142, 104387. doi: 10.1016/j.appet.2019.104387

Hughes, S. O., Power, T. G., Orlet Fisher, J., Mueller, S., \& Nicklas, T. A. (2005). Revisiting a neglected construct: parenting styles in a child-feeding context. Appetite, 44(1), 83-92. doi: 10.1016/j.appet.2004.08.007

Kumar, S., \& Kelly, A. S. (2017). Review of Childhood Obesity: From Epidemiology, Etiology, and Comorbidities to Clinical Assessment and Treatment. Mayo Clinic Proceedings, 92(2), 251-265. doi: 10.1016/j.mayocp.2016.09.017

Marshall, S. A., Ip, E. H., Suerken, C. K., Arcury, T. A., Saldana, S., Daniel, S. S., \& Quandt, S. A. (2018). Relationship between maternal depression symptoms and child weight outcomes in Latino farmworker families. Maternal \& Child Nutrition, 14(4), e12614. doi: 10.1111/mcn.12614

Martinez, S. M., Rhee, K. E., Blanco, E., \& Boutelle, K. (2017). Latino mothers' beliefs about child weight and family health. Public Health Nutrition, 20(6), 1099-1106. doi: 10.1017/S1368980016002962

Melis Yavuz, H., \& Selcuk, B. (2018). Predictors of obesity and overweight in preschoolers: The role of parenting styles and feeding practices. Appetite, 120, 491-499. doi: 10.1016/j.appet.2017.10.001

Olvera, N., \& Power, T. G. (2010). Brief report: parenting styles and obesity in Mexican American children: alongitudinal study. Journal of Pediatric Psychology, 35(3), 243-249. doi: 10.1093/jpepsy/jsp071

Shamah-Levy, T., Vielma-Orozco, E., Heredia-Hernández, O., Romero-Martínez, M., Mojica-Cuevas, J., Cuevas-Nasu, L., ... Rivera-Dommarco, J. (2020). Encuesta Nacional de Salud y Nutrición 2018-19: Resultados Nacionales. Cuernavaca, México: Instituto Nacional de Salud Pública.

The Center for Epidemiologic Studies Depression Scale Revised. (2020). Retrieved from https://cesd-r.com/

Van Dam, N. T., \& Earleywine, M. (2011). Validation of the Center for Epidemiologic Studies Depression Scale--Revised (CESD-R): Pragmatic depression assessment in the general population. Psychiatry Research, 186(1), 128-132. doi: 10.1016/j.psychres.2010.08.018

Vaughn, A. E., Ward, D. S., Fisher, J. O., Faith, M. S., Hughes, S. O., Kremers, S. P., ... Power, T. G. (2016). Fundamental constructs in food parenting practices: a content map to guide future research. Nutrition Reviews, 74(2), 98-117. doi: 10.1093/nutrit/nuv061

Vollmer, R. L. (2019). Parental feeding style changes the relationships between children's food preferences and food parenting practices: The case for comprehensive food parenting interventions by pediatric healthcare professionals. Journal for Specialists in Pediatric Nursing, 24(1), e12230. doi: 10.1111 jspn. 12230

World Health Organization. (2020a). Childhood overweight and obesity. WHO. Retrieved from https://www.who.int/dietphysicalactivity/childhood/en/

World Health Organization. (2020b). Depression. WHO. Retrieved from https:// www.who.int/news-room/fact-sheets/detail/depression

World Health Organization. (2009). WHO AnthroPlus for personal computers Manual: Software for assessing growth of the world's children and adolescents. Geneva: WHO, 2009. Retrieved from http://www.who.int/growthref/tools/en/ and https://www.who.int/growthref/tools/who_anthroplus_manual.pdf 